\title{
Effect of long-chain fatty alcohols from orujo olive oil on nitric oxide and eicosanoid generation
}

\author{
M. A. Fernández Arche ${ }^{1}$, R. de la Puerta Vázquez ${ }^{1}$, A. Márquez Martín ${ }^{1}$ and V. Ruiz-Gutierrez ${ }^{2}$ \\ ${ }^{1}$ Department of Pharmacology, School of Pharmacy, University of Seville, C/ Profesor García Gonzalez No. 2 \\ and ${ }^{2}$ Instituto de la Grasa (CSIC), Av. Padre García Tejero No. 4, 41012 Seville, Spain
}

Olive pomace oil ('orujo' oil) is an olive oil product suitable for human consumption that is traditionally produced in Spain ${ }^{(1)}$. The nonacylglycerol component of this oil is a good source of interesting minor components, e.g. triterpenes ${ }^{(2)}$, or fatty alcohols, derived from waxy materials. Tetracosanol $\left(\mathrm{C}_{24} \mathrm{OH} ; 30 \%\right)$, hexacosanol $\left(\mathrm{C}_{26} \mathrm{OH} ; 37 \%\right)$ and octacosanol $\left(\mathrm{C}_{28} \mathrm{OH} ; 15 \%\right)$ are the major constituents of the long-chain fatty alcohol (LCFA) fraction isolated from orujo olive oil ${ }^{(3)}$. A similar mixture of long-chain alcohols, termed 'policosanol' and purified from waxy materials of different sources such as sugar cane, bees wax, rice bran or spinach, have shown many beneficial physiological activities ${ }^{(4,5)}$. The present study focused on the effect of LCFA isolated from orujo olive oil on $\mathrm{NO} \mathrm{PGE}_{2}$ and TNF $\alpha$ release by a lipopolysaccharide (LPS)-stimulated murine macrophage cell line (RAW-264.7) as well as the effect on thromboxane $\mathrm{B}_{2}\left(\mathrm{TXB}_{2}\right)$ generation by A-23187-stimulated rat peritoneal neutrophils (PMN). Nitrite (as an index of NO generation) levels were determined by a fluorometric method. $\mathrm{PGE}_{2}, \mathrm{TNF} \alpha$ and $\mathrm{TXB}_{2}$ production were quantified by sandwich immunoassay.

LCFA significantly and dose-dependently decreased the NO production in LPS-stimulated RAW-264.7 cell line macrophages (Fig. 1). Western-blot analysis for inducible NO synthase (iNOS) showed that NO reduction was a consequence of the $100 \%$ inhibition of iNOS expression at a dose of $100 \mu \mathrm{g} / \mathrm{ml}$ (Fig. 2). By contrast, LCFA scarcely affected $\mathrm{PGE}_{2}$ levels (Fig. 1). TNF $\alpha$ production was also

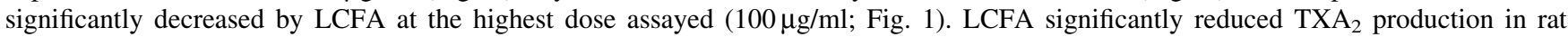
PMN stimulated with A-23187 (Fig. 3).
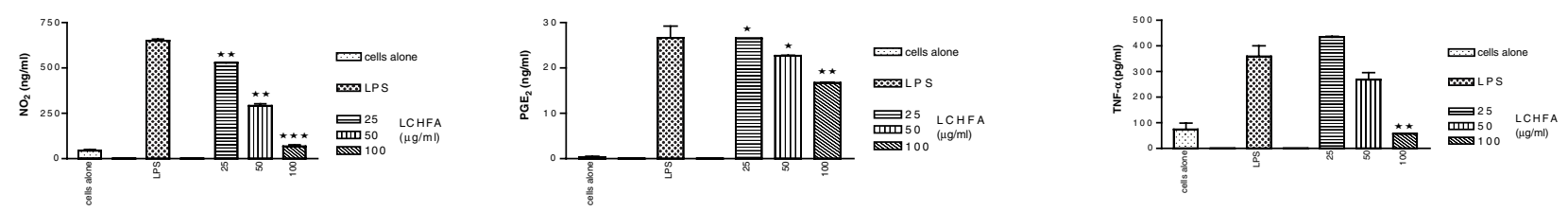

Fig. 1. Effect of LCFA on NO, PGE 2 and TNF $\alpha$ produced by LPS $(10 \mu \mathrm{g} / \mathrm{ml})$-stimulated RAW-264.7 murine macrophages $\left(1 \times 10^{6}\right.$ cells/ml $)$. Mean values were significantly different from those for LPS control group: $* * P<0.01$, $* * * P<0.001$.

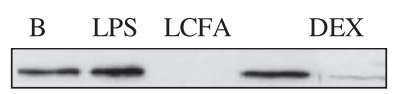

$\%$ OD $40 \quad 100 \quad 0 \quad 4$

Fig. 2. Effect of LCFA subfraction on iNOS expression and densitometric analysis in $R A W 264.7$ cells. DEX, dexamethasone; OD, optical density.

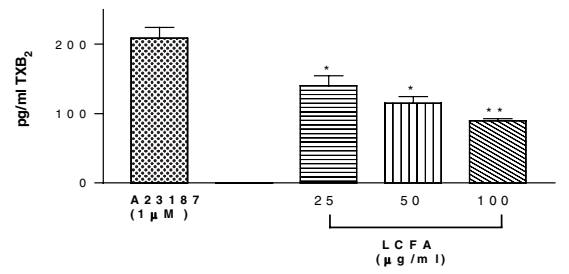

Fig. 3. Effect of LCFA on $\mathrm{TXB}_{2}$ produced by A-23187-stimulated rat PMN. Mean values were significantly different from the control value: $* P<0.05, * * * P<0.001$

\footnotetext{
1. Perona JS, Aracemis C, Ruiz-Gutierrez V \& Catalá A (2005) J Agric Food Chem 53, 730-735.

2. Perez Camino MC \& Cert A (1999) J Agric Food Chem 47, 1558-1562.

3. Marquez A (2007) Doctoral Thesis, Universidad de Sevilla.

4. Taylor JC, Rapport L \& Lockwood GB (2003) Nutrition 19, 192-195.

5. Singh DK, Li L \& Porter TD (2006) J Pharmacol Exp Ther 318, 1020-1026.
}

These results showed that LCFA isolated from 'orujo' oil has a protective effect on some mediators implicated in the development of inflammatory damage in these experimental models and suggest its potential value as a functional component of the olive pomace oil.

This study is part of the project AGL2005-00572/ALI, financially supported by the Comision Interministerial de Ciencia y Tecnologia (CICYT). 